\title{
12
}

\section{A PROBLEMATISATION OF INCLUSION AND EXCLUSION}

\author{
Trade-offs and nuances in the \\ digitalisation of African agriculture
}

Mariette McCampbell, Kelly Rijswijk, Hannah Wilson, and Laurens Klerkx

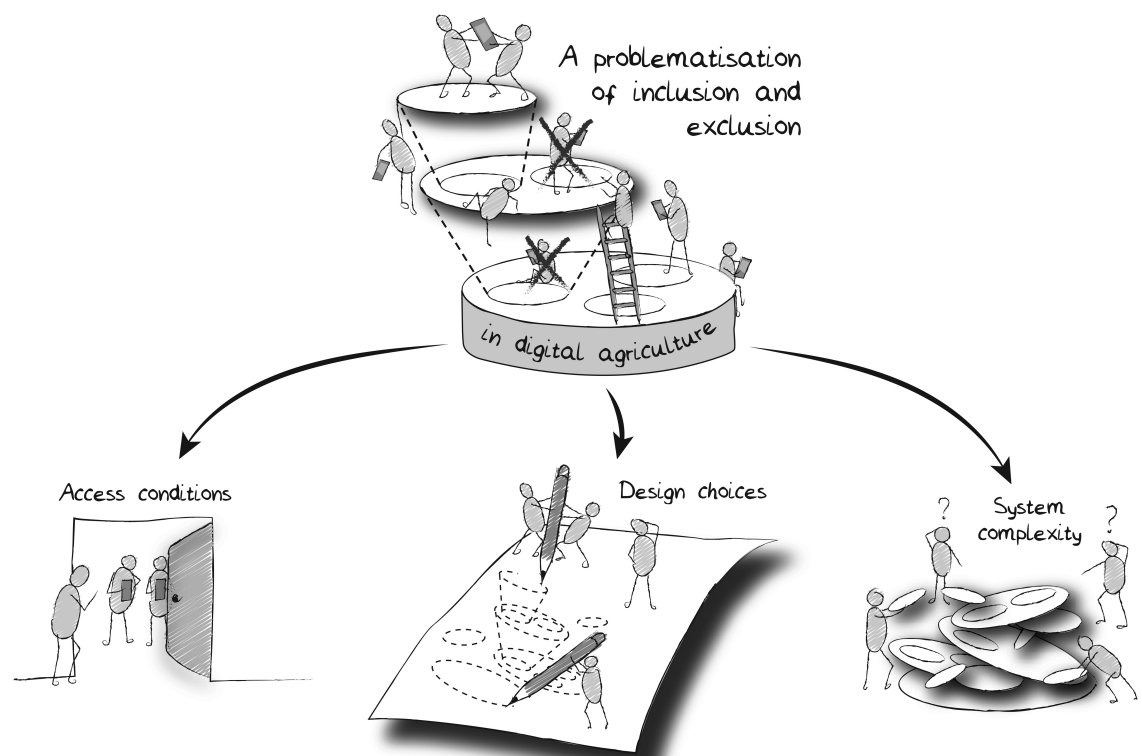

\section{Introduction}

The use of digital technologies to enhance efficiency of production, processing, and trade, aiming to improve the profitability and sustainability of organisations and industries, has become a global trend in a wide range of industries including in African smallholder agriculture (Klerkx et al., 2019; Munthali et al., 2018). The digitalisation process concerns the use of digital technologies 
and infrastructures in businesses, economy, and society, restructuring social and professional life through digital communication and social media (Rijswijk et al., 2020). Another important concept related to digitalisation is datafication, defined as the transformation through which objects, relationships, events, and processes become data points that are machine-readable and analysable by digital technologies using data analytics, machine learning, and complex algorithms (Williamson, 2018).

A popular assumption is that digitalisation is ultimately beneficial for everyone, and truly transforms agriculture (Klerkx et al., 2019). This discourse is especially commonplace in the context of digitalisation efforts for humanitarian, aid, and development objectives (Cinnamon, 2020; Mann, 2018), like many of the present-day digital interventions in African agriculture (Mann and Iazzolino, 2019; Tsan et al., 2019). In practice, the true socio-economic impact of digitalisation processes in Africa's agricultural system is yet to be seen, and recent critical analyses of digitalisation in agriculture point to unequal distribution of benefits and harm (Rotz et al., 2019; Van der Burg et al., 2019). This unequal distribution relates to mechanisms of social inclusion and exclusion, terms that are generally used to organise people (or groups) according to criteria that define who is 'in' and who is 'out' (Graham and Sweller, 2011). For example, when assessing access of African farmers to weather information via a mobile phone, one could take geography, gender, age, wealth, etc. into account; but in practice, processes of inclusion and exclusion are more complex.

This chapter has the objective to unravel this complexity in digitalisation processes in African smallholder agriculture in three levels: (1) access conditions in relation to a specific digital technology; (2) design choices in relation to a digital innovation package; and (3) system complexity in relation to the digital agricultural system. To date these potential causes and impacts of inclusion and exclusion are underexplored in an African smallholder agricultural context, especially when looking beyond access conditions. There is a knowledge gap about the understanding of inclusion and exclusion surrounding digitalisation of agriculture in the African context. With such a focus on Africa, this chapter builds on lessons learned from both a Global North and South context, providing a broad overview of factors causing inclusion and exclusion and establishing a more nuanced discourse around inclusion and exclusion related to digital agriculture-understood as broad digitalisation both on- and off-farm, e.g. in the broader value chain - and its impact on people's lives.

\section{Conceptual framing of social inclusion and exclusion}

Notions of inclusion and exclusion in sociology address structural inequalities faced by different groups; traditionally mostly women, and also disabled, illiterate, indigenous, or (rural) poor people. Inclusiveness has long been promoted as a strategy to alleviate poverty, increase economic growth, generate employment, progress horizontal and vertical (gender) equality, and improve well-being 
(McKinley, 2010). In the African context, there is significant attention for inclusive development, innovation, and business (Opola et al., 2020; Pouw et al., 2019). Inclusion and exclusion are often used as binary distinctions that are defined by people either falling inside or outside specific social categories, and above or below specified limits (Mascareño and Carvajal, 2015). Within this context the good, expectable, and normal are attributed to inclusion, with exclusion being the negative opposite (Parsons, 1965). However, modern societies allow for a people and groups to be simultaneously included and excluded: hence inclusion and exclusion are not an 'either-or' matter, since no person is fully included or excluded (Mascareño and Cavajal, 2015). Stichweh and Windolf (2009) add a distinction between including exclusion and excluding inclusion, i.e., how inclusion in one group can result in (indirect) exclusion from another and vice versa. Hence, the distinction between inclusion and exclusion is more complex than a static observation of who is 'in' versus 'out' (Fitoussi and Rosanvallon, 1997) and should be approached as a process taking place within a particular social context, instead of a dichotomy between insiders and outsiders.

The thinking about inclusion and exclusion should move beyond binary terms and pay particular attention to the formation and maintenance of various kinds of power Du Toit (2004). In this regard, Sen (2000) identified unfavourable forms of inclusion; for example, as pointed out by Joseph (2014), a subordinated type in which inclusion is not evenly distributed. Another example is seen in agricultural value chains in which the profits are unevenly distributed between farmers, traders, and sellers.

Digital responses to address subordinated inclusion comprise applications that connect producers and buyers that bypass the middlemen (Aker, 2016) and e-auctions (Joseph, 2020). Unfavourable inclusion can also be illusive, so that the outcome of being included is then the same as the outcome of being excluded (Joseph, 2014). An example of illusive inclusion is when a farmer is selected to participate in a survey of a development project and expects to benefit from this. Yet, in practice the farmer never hears from this project again, nor witnesses results.

Sen's (2000) framework also recognises constitutive, instrumental, active, and passive exclusion (and unfavourable inclusion). Constitutive exclusion has a direct impact on the person excluded, such as female farmers not being invited for agronomic training and therefore not developing the same knowledge as male farmers. Instrumental exclusion leads to exclusion through causal linkages, for instance, when a farmer cannot access credit to buy inputs and equipment to increase farm production and escape poverty. Active exclusion is deliberate, as in purposely not inviting women for agronomic training, while passive exclusion is non-deliberate and the result of social processes. In the latter case, exclusion is an unintended consequence of some decision or action, such as early-warning messages about the outbreak of a crop disease not reaching poorer farmers because they cannot afford the smartphone needed to receive the message. Nevile (2007) argues that when active forms of exclusion (or unfavourable inclusion) act as 
causal factors, focus should be on reasons and possible justifications for the deliberate decision to exclude. For passive forms of exclusion (or unfavourable inclusion), the focus should be on ways to mitigate unintended consequences.

\section{Observing mechanisms of inclusion and exclusion in digital agriculture}

Existing digital development discourse characterises (data) inequalities as 'a basic problem of inclusion/exclusion, based on the notion that inequality in diffusion of, access to, and use of data can widen development gaps between individuals, groups, and nations' (Cinnamon, 2020, p. 215), a framing that is criticised for being insufficient for explaining or addressing causes, forms, and consequences of inequalities. Hence, digital and data inclusion and exclusion always occur in a specific context. Figure 12.1 presents three contextual levels at which inclusion and exclusion takes place: the level of a (single) digital technology; a digital innovation package (i.e., a design of digital hardware and/or software, and the institutional arrangements to use it); and a digital agricultural system (i.e., the configuration of various rival and/or adherent and/or synergetic innovation packages and the socio-cultural context in which they need to operate).

Illustrates how these contextual levels relate to each other. The digital technology level represents the most tangible and transparent level. Studies with an African focus have primarily concentrated on this level, studying who can and who cannot access a digital technology, and the conditions required for access. This access can be further divided into five sub-categories: availability, affordability, awareness, abilities, and agency (Roberts and Hernandez, 2019).

\section{Digital technologies and access conditions: looking at digital divides}

In the following sections, we further unravel the three contextual levels introduced in the conceptual framework based on existing literature. Starting with the contextual level of digital technologies, we discuss different forms of inclusion and exclusion that together present a variety of (potential) areas of concern in relation to digital agriculture as identified in Table 12.1.

The advantage of focusing on a specific digital technology, and access to it, is that inclusion and exclusion are then relatively tangible and transparent. But as seen in Figure 12.1, only the tip of the iceberg is then visible. Negative socio-economic impacts of digitalisation have often been summarised under the umbrella of the so-called 'digital divide.' Access issues in Africa are generally recognised as key reasons for digital divides between the Africa/Global North, urban/rural, and rich/poor pairings (Trendov, 2019). This leads to social and economic marginalisation and uneven socio-economic development (Rijswijk et al., 2020; Rotz et al., 2019; Salemink et al., 2017). Thus, known factors like 


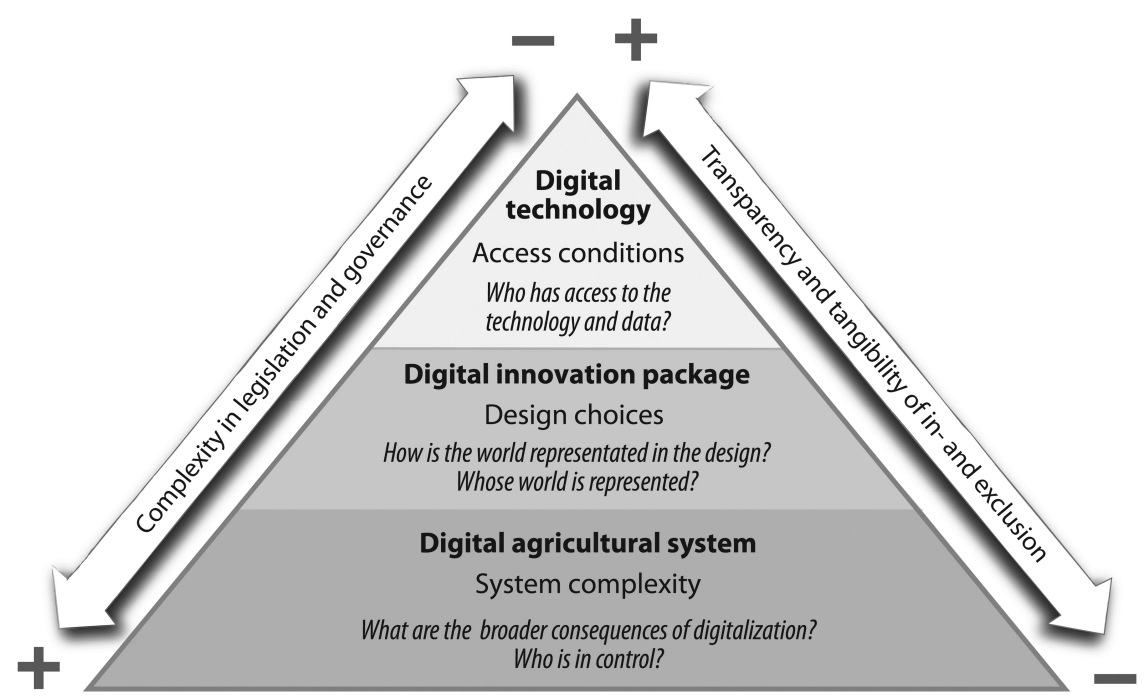

FIGURE 12.1 Relationship between the three levels at which digital and data inclusion and exclusion may appear, with increasing or decreasing complexity in the vertical axis governing the digital systems, and marking how tangible and transparent inclusion and/or exclusion are

location, age, gender, ethnicity, wealth status, and education level, determine access to and use of digital technologies by individuals, and they foster individuals' inclusion or exclusion to potential or assumed benefits of digitalisation.

Digital divides are born from inequalities in access, literacy, cost, or service relevance, and continue to exist despite being a key challenge for achieving developmental and economic goals, regardless of whether a country is rich or if nation-wide access has increased (USAID, 2020). The disadvantage of women in African smallholder farming communities has received particular attention (OECD, 2018). Studies systematically show the existence of a gender digital divide, with men nearly always being better off (Porter et al., 2020) and women benefitting less than they could (GSMA, 2019).

Additionally, the increasing importance of data (that is, of datafication) has led to the emergence of a specific new type of divide: the data divide. The data divide refers to asymmetries between the 'data haves' and 'have-nots' (Scholz et al., 2018). According to Cinnamon (2020, p. 228), data divides matter because 'access to data production and analytics in some cases actually has the reverse effect, the instantiation of new harms and the widening of inequalities.'

\section{Challenges arising from digital divides}

Availability here implies various forms of access: material (digital hardware, software, and data); infrastructure (required to access and use those hardware, 
204 McCampbell, Rijswijk, Wilson, and Klerkx

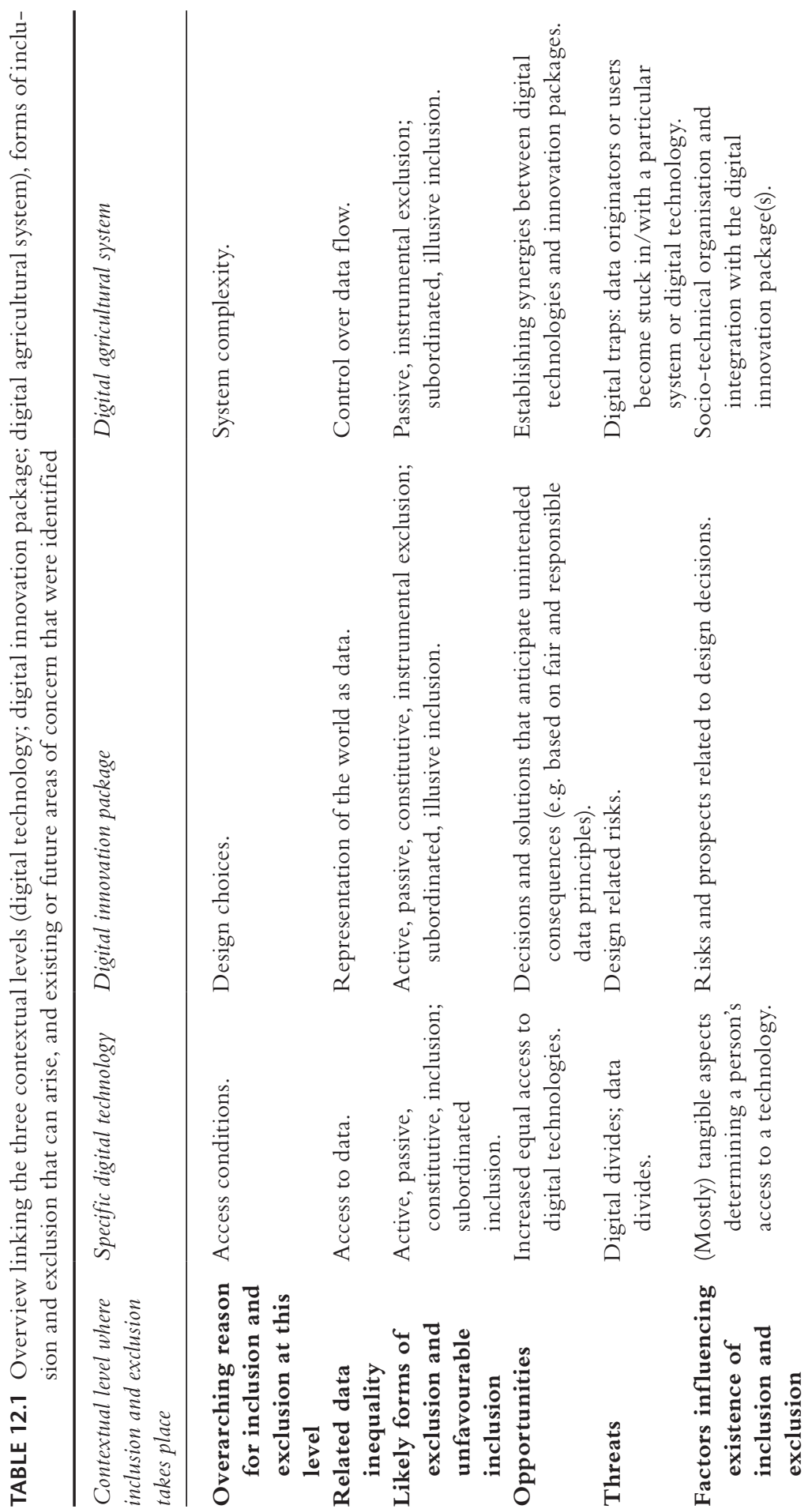



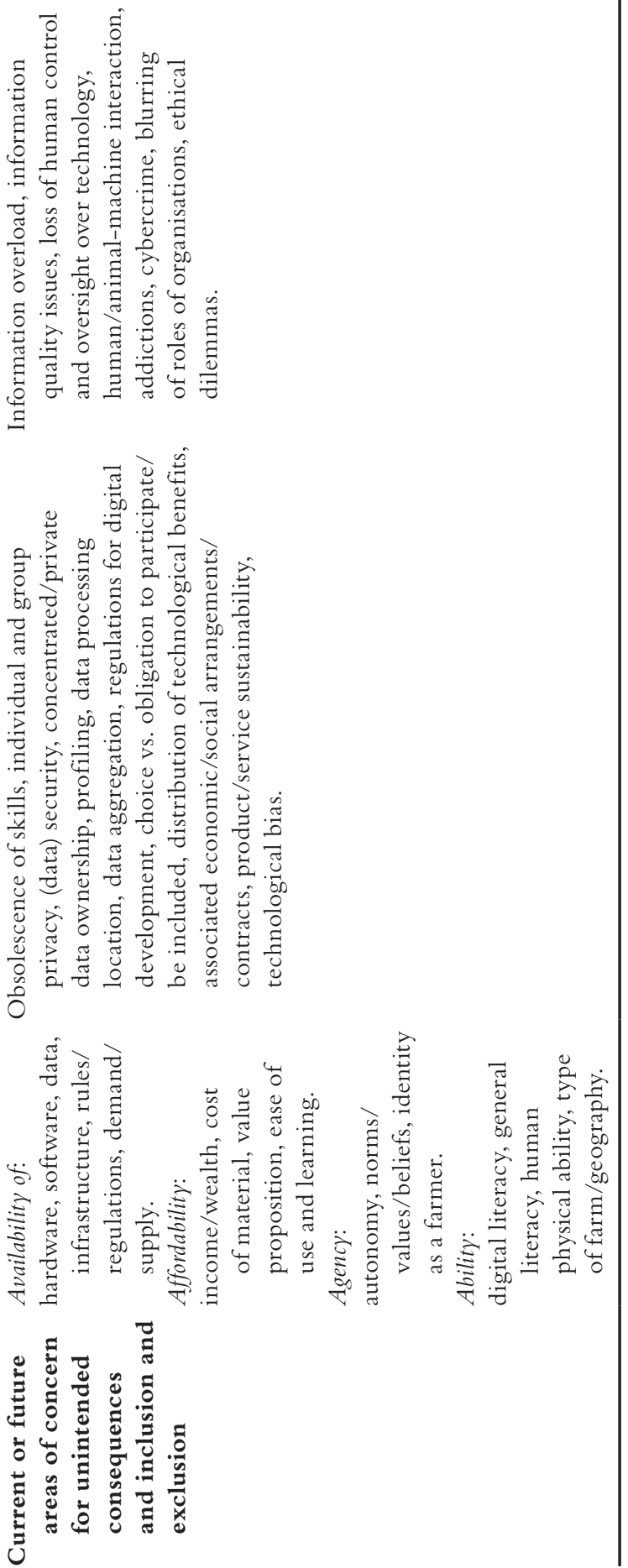
software, and data); institutional (rules and regulations); market (demand and supply); and suitability context (is the digital technology a good and fair fit for the context?). Availability of hardware, software, infrastructure, and suitable policies are outstanding issues in African countries (Ezeomah and Duncombe, 2019; Mann, 2018; Trendov, 2019;) leading mostly to passive and constitutive exclusion although active exclusion is also possible. Concerns arise that universal access and the increasing power of data in economic governance, together with the lobby of big tech companies for strategically advantageous regulation, puts African countries at risk of data extraction that benefits foreign rather than domestic economies (Mann, 2018). In such cases there is a risk of unfavourable inclusion; specifically, of subordinated inclusion.

Affordability relates to economic capacity: capital required to access digital technologies; one-off or recurring material investments; and whether the technology delivers profit. Inclusion and exclusion here result from economic inequalities between farmers and farmers and other stakeholders, thus resulting in passive and constitutive exclusion. Affordability challenges may exacerbate with extremely high initial investments, or recurring expenses. Continuous investments become more problematic in case of technological lock-in and pathdependency, tying a farmer to one particular company or organisation due to proprietary software, inability to access farm data without a subscription plan, or inoperability with competitive offers (Bronson, 2018). Considering the income levels of African smallholder farmers combined with general absence of loan facilities, practically any investment may be considered 'extremely high' in this context. In addition, social needs and values influence perceptions about affordability. For example, the common conception that 'time is money' in highincome countries legitimates investments in labour and time saving technologies. Most African farmer's time or labour however is considered 'for free,' especially women's time, resulting in a totally different cost-benefit calculation (Grassi, 2015). Additionally, whether investments guarantee profit return or not matters, especially in volatile markets with fluctuating agriculture produce prices (Rotz et al., 2019). These affordability issues may all result in exclusion of farmers' access to digital technologies, by definition (e.g. unable to buy a phone) or by choice (e.g. unwilling to invest in a phone).

Another issue for digital agricultural technologies in the context of African smallholder farming is users' capabilities, ease of learning and using a digital technology, and whether farmers can afford investment in additional training and resources (e.g. time, effort, physical strength). A reason for poor adoption is that farmers - especially the elderly, and females - struggle with using digital tools, particularly when smartphone based (Ezeomah and Duncombe, 2019). This relates to user ability in terms of digital and general literacy, and physical ability. Literacy is a well-known challenge in agricultural development, creating barriers for farmers with limited or no education. Digital literacy is a newer issue relating to skills and knowledge required to use digital technologies, such as using hardware and software, and making sense of data produced or received. 
In other words, digital technologies need to fit farmers' level of tech savviness so as to prevent passive and constitutive exclusion.

Agency and awareness about the socio-cultural context are less tangible issues that are often embedded in the socio-cultural make up of agricultural communities and therefore not directly observable. However, they are critical factors that influence adoption decisions and passive as well as constitutive exclusion, especially in cases of non-adoption or de-adoption, regardless of good availability, affordability, and ability of users. An example of constitutive exclusion is when it is considered socio-culturally inappropriate for a woman to use digital technologies.

Reasons for inequalities in access to digital technologies and data are not limited to observable, tangible, or seemingly individual factors (like age, gender, and wealth) but extend to more unobservable, intangible, and aggregated issues too, which, as we will see in the next sections, relate to the other contextual levels of Figure 12.1, viz. the digital innovation package, and the digital agricultural system.

\section{Digital innovation packages and design choices: deciding about the design and anticipating design consequences}

Digital technologies and interventions are designed with a specific objective and desired outcomes in mind. Decisions about the design determine, for example, the physical, front-end design (e.g. the hardware and software interface) and system or back-end design (e.g. programming languages used, location of databases, interoperability with other systems). These design choices around digital technologies and innovation packages are always accompanied by risks, as it requires decision making about the world that the technology and the collected data collected represents, i.e., whose world is represented, and how this is done. These decisions alter our physical world and how we operate in it, potentially causing unequal opportunities (Cinnamon, 2020). Hence, design related impacts intended; unintended consequences are likely, which in turn can lead to all forms of exclusion and unfavourable inclusion. Design choices are ultimately accompanied by trade-offs; saying 'yes' to one design feature usually equals saying 'no' to other features. Those trade-offs make exclusion almost inevitable as designfor-all or one-size-fits-all solutions are highly complex and oftentimes simply impossible. An example trade-off is the anticipation that progressing digitalisation in African agriculture will reduce demand for traditional farm-labourers, but that digitalisation could be a net job-creator too, offering opportunities for those with the right skills, like the many highly educated African youth (Heeks, 2020; Tsan et al., 2019). This non-deliberate loss of particular jobs is, in turn, an example of unequal distribution of benefits as well as instrumental and passive exclusion. Design choices should ideally anticipate unintended consequences that could become design related risks (Rijswijk et al., 2020). In this, transparency and accountability are desirable. 
Designing digital innovation packages is also about distributing power among actors, with some becoming more influential than others. But how are benefits from digital technologies distributed among different actors, such as technology developers, users, data originators, and data owners? Do design choices contribute to reducing inclusion and equal distribution of benefits, or do they create marginalisation of individuals or groups? These questions relate to subordinated inclusion, e.g. one actor will benefit more from an innovation design than another. Digital agriculture is often associated with high-tech, smart technologies and large-scale, input-intensive farms. Scholars have observed that wealthier, large-scale, commercial farmers benefit more from digitalisation in agriculture (Bronson, 2018). Hence digitalisation may support a limited number of specific agricultural production systems at the expense of others (Bronson and Knezevic, 2016; Klerkx et al., 2019). Others argue that visions for the role of digital technologies support perpetuation of a status quo that prioritises maximisation of global agricultural production (Lajoie-O'Malley et al., 2020). Then again, in the absence of large numbers of commercial farms to date, current digitalisation initiatives in Africa focus mostly on reaching smallholder farmers. The widespread use of smartphone-based applications and platforms in digitalisation processes, for now, makes the socio-economic status of users less influential. Nevertheless, in practice wealthier or more literate farmers have the advantage of an overall larger capacity to buy fertilisers, hybrid seeds, get credit, or access digital hardware and infrastructure required to get access to information in the first place (Mann, 2018); therefore they are better able to benefit from what digital technologies have to offer. This as an example of illusive inclusion; the design of a digital technology may be inclusive for all farmers, yet they cannot all benefit from it because of the inability to truly use or act upon it.

\section{Digital agricultural systems and system complexity: emerging mechanisms of inclusion and exclusion in digital agriculture}

In this section we cover the third level, system complexity, or the composition of elements that together make up the digital agricultural system and the sociotechnical organisation within it. The digital agricultural system is complex in multiple ways: variations in crop production systems and value chains; national and international jurisdictions; the multitude of actors involved; and the evergrowing diversity of digital technologies and technological packages which may or may not be interconnected or interoperable. The complexity and motions of digital systems make prediction and visibility of different forms of inclusion and exclusion challenging.

System complexity also increases uncertainty about issues such as the quality of data and information as input and output of digital systems. A possible response is more technological integration. Integration offers opportunities for synergies and reduced complexity, yet a lack of integration can become a digital 
trap (Rijswijk et al., 2020). For example, a user may become stuck with a particular piece of hardware or software that is not interoperable with other items, or cannot be updated. Interoperability and coupling of systems is critical. In contrast, too tight coupling of systems leads to vulnerability and potential domino effects, i.e., if one system fails all fail. How do digital traps and domino effects relate to inclusion and exclusion? The first can result in perpetuating inclusion or exclusion: those included remain included, those excluded remain excluded. Instrumental exclusion may be the outcome of the latter because of the causal linkages between systems.

The presence of digital technologies and data-based decision making inherently affects real-life interactions, such as between people or people and animals. Traditional human-to-human interactions become moderated or replaced by machines, changing relationships between humans and their natural, technical, and social environments and allowing for less empathy, trust building, and judgment of intentions and preferences (Scholz et al., 2018). In cultures where human-to-human interaction has important cultural value, like most African cultures, trust is important for acceptance of (digital) technologies (Aker et al., 2016). According to Scholz et al. (2018), data can be a disturbing variable and distractor for sharing experiences and knowledge, taking away agency from the human individual.

More concretely, digital systems rely on data input to operate. However, data inconsistency is a known problem, especially with large datasets from heterogeneous sources, needing investment in rigorous efforts to reduce data noise and correct inconsistencies (Philip Chen and Zhang, 2014). Another challenge with data aggregation is the need to consider variances in how data is interpreted. Although mainstreaming interpretations enhances interoperability, it also raises the question of whether 'hybrid' interpretations are trustworthy or provide a new form of interpretative doubt (Mansour et al., 2016), and whether they support or undermine equality. For example, the outcome of interpretational mistakes may be that people are passively included or excluded, which is hard to control for and may have unforeseen consequences.

But, who is responsible for those consequences? Governing digital agricultural systems is inherently difficult, especially when they are coupled or operating across-borders. Yet this also influences control over digital technologies and, more importantly, control over who uses data, where, when, and for what purposes (Cinnamon, 2020) as well as who can be held accountable. In combination with uncertainty about emerging effects of digitalisation, accountability leads to various concerns about misuse of data and blurring roles and responsibilities in the digital agriculture system. Currently, roles, actors, and data owners are not clearly defined; neither are governance models, establishing who is accountable for what. Additionally, actors in the agricultural sector need to redevelop their identity and build new capacity and expertise, moving from being classical agricultural or humanitarian organisations working on crop improvement, face-to-face extension services, or emergency support to people, to designers and 
operators of digital platforms and systems which requires different skillsets and expertise. Within this complex and opaque environment it is easy for all kinds of inclusion and exclusion to emerge, being at the same time difficult to anticipate. Additionally, taking action against exclusion or unfavourable inclusion may not be in the interest of the actors who are in control, yet institutional arrangements fall short in effectively controlling this.

\section{Rethinking inclusion and exclusion for the context of digital agriculture}

The previous sections showed that as opportunities to capture unique properties about individuals, their farm, and their behaviour (habits, norms and values, likes and dislikes, recurring decisions) expand, it more and more matters who you are and what you do, both as an individual and a company or organisation. We have seen that digital technologies may lead to various mechanisms of inclusion and/or exclusion of actors and that increasingly these mechanisms may be intangible in nature (e.g. algorithmic bias, or user profiling). Intangible factors, resulting from design choices and system complexity, become powerful determinants of who is included or excluded and whether inclusion and exclusion is beneficial or harmful due to e.g. expanding access to data, aggregation of data, and capacity for data computation and manipulation. We previously noted that in relation to African agriculture, focus has been biased towards access conditions, while attention for design choices and system complexity lags behind. The latter two are rarely considered, or only in form of critique-such as exclusion of actors in the design process and of actors from the benefits of data generated outputs-without offering solutions to the emerging challenges. Digital technologies meanwhile present themselves as a double-edged sword: being included may be both beneficial and harmful. Similarly, included individuals may gain agency at one contextual level, but lose it at another level.

In this chapter, we unravelled the known and future impacts of digitalisation processes on inclusion and exclusion in African agriculture and showed the difficulty to identify 'right' from 'wrong.' Ultimately, digitalisation comes with trade-offs: people generally lack control in being included somewhere and excluded elsewhere, and vice versa. Although designers and implementers of digital technologies may anticipate many unintended consequences, some fall into the category of unknown consequences and simply cannot be predicted beforehand. Additionally, it is not always possible to control for all unintended consequences, especially when they require transformations beyond the technological design such as in the institutional or socio-cultural environment. Hence, the dichotomy of inclusion and exclusion and the inherent normative assumption that inclusion is always good and exclusion always bad, demands revisiting. The perception that technology and technological progress are inherently good and needed for growth is fundamentally flawed when it comes to digital technologies. Instead, the trade-offs and unintended consequences that come with 
digitalisation and datafication at the three contextual levels that we discussed in this chapter should receive more recognition and consideration.

\section{Acknowledements}

This chapter was partly based on and funded through the DESIRA project. This project received funding from the European Union's Horizon 2020 research and innovation programme under grant agreement No 818194. Additional support for this work came from the CGIAR Research Program on Roots, Tubers and Bananas (RTB) supported by CGIAR Trust Fund contributors. Disclaimer: the content of this chapter does not reflect the official opinion of the European Union, RTB, or CGIAR. Responsibility for the information and views expressed therein lies entirely with the author(s).

\section{References}

Aker, J. C., Ghosh, I. and Burrell, J. (2016). The promise (and pitfalls) of ICT for agriculture initiatives. Agricultural Economics, 47, 35-48.

Bronson, K. and Knezevic, I. (2016). Big data in food and agriculture. Big Data \& Society, 3(1), 2053951716648174.

Bronson, K. (2018). Smart farming: Including rights holders for responsible agricultural innovation. Technology Innovation Management Review, 8(2), 7-14.

Cinnamon, J. (2020). Data inequalities and why they matter for development. Information Technology for Development, 26(2), 214-233.

Philip Chen, C. L. and Zhang, C.-Y. (2014). Data-intensive applications, challenges, techniques and technologies: A survey on Big Data. Information Sciences, 275, 314-347.

Du Toit, A. (2004). "Social exclusion" discourse and chronic poverty: A South African case study. Development and Change, 35(5), 987-1010.

Ezeomah, B. and Duncombe, R. (2019). The role of digital platforms in disrupting agricultural value chains in developing countries. International Conference on Social Implications of Computers in Developing Countries, Springer, 231-47.

Fitoussi, J. P. and Rosanvallon, P. (1997). La nueva era de las desigualdades. Buenos Aires: Manantial.

Graham, L. J. and Sweller, N. (2011). The inclusion lottery: Who's in and who's out? Tracking inclusion and exclusion in New South Wales government schools. International Journal of Inclusive Education, 15(9), 941-953.

Grassi, F., Landberg, J. and Huyer, S. (2015). Running out of time. The reduction of women's work burden in agricultural production. Rome: Food and Agriculture Organization of the United Nations.

GSMA. (2019). Connected women: The mobile gender gap report 2019. GSMA.

Heeks, R. (2020). ICT4D 3.0? Part 2-The patterns of an emerging "digital-fordevelopment" paradigm. The Electronic Journal of Information Systems in Developing Countries, 86(3), e12123.

Joseph, K. J. (2014). Exploring exclusion in innovation systems: Case of plantation agriculture in India. Innovation and Development, 4(1), 73-90.

Joseph, K. J. (2020). Commodity markets, computers and inclusive development: A Study of Marketing and Price Formation of Cardamom with e-Auctions. Dordrecht: Springer. 
Klerkx, L., Jakku, E. and Labarthe, P. (2019). A review of social science on digital agriculture, smart farming and agriculture 4.0: New contributions and a future research agenda. NJAS-Wageningen Journal of Life Sciences, 90-91, 100315.

Lajoie-O'malley, A., Bronson, K., Van Der Burg, S. and Klerkx, L. (2020). The future(s) of digital agriculture and sustainable food systems: An analysis of high-level policy documents. Ecosystem Services, 45, 101183.

Mann, L. (2018). Left to other peoples' devices? A political economy perspective on the big data revolution in development. Development and Change, 49(1), 3-36.

Mann, L. and Iazzolino, G. (2019). See, nudge, control and profit: Digital platforms as privatized epistemic infrastructures. Bangalore: IT for Change.

Mansour, I., Sahandi, R., Cooper, K. and Warman, A. (2016). Interoperability in the heterogeneous cloud environment: A survey of recent user-centric approaches. In: ICC 2016 proceedings of the International Conference on Internet of Things and Cloud Computing, 62: ACM.

Mascareño, A. and Carvajal, F. (2015). The different faces of inclusion and exclusion. Cepal Review, 116, 127-141.

McKinley, T. (2010). Inclusive growth criteria and indicators: An inclusive growth index for diagnosis of country progress. Manila: ADB Sustainable Development.

Munthali, N., Leeuwis, C., van Paassen, A., Lie, R., Asare, R., van Lammeren, R. and Schut, M. (2018). Innovation intermediation in a digital age: Comparing public and private new-ICT platforms for agricultural extension in Ghana. NJAS - Wageningen Journal of Life Sciences, 86/87, 64-76.

Nevile, A. (2007). Amartya K. Sen and social exclusion. Development in Practice, 17(2), 249-255.

OECD (2018). Bridging the digital gender divide - include, upskill, innovate. Paris: OECD.

Opola, F.O., Klerkx, L., Leeuwis, C., \& Kilelu, C. W. (2021). The hybridity of inclusive innovation narratives between theory and practice: A framing analysis. The European Journal of Development Research. 33, 626-648. https://doi.org/10.1057/s41287-020 -00290-z@,

Parsons, T. (1965). Full citizenship for the negro American? A sociological problem. Daedalus, 94(4), 1009-1054.

Porter, G., Hampshire, K., Abane, A., Munthali, A., Robson, E., De Lannoy, A., et al. (2020). Mobile phones, gender, and female empowerment in sub-Saharan Africa: Studies with African youth. Information Technology for Development, 26(1), 180-193.

Pouw, N., Bush, S. and Mangnus, E. (2019). Editorial overview: Inclusive business for sustainability. Current Opinion in Environmental Sustainability, 41, A1-A4.

Rijswijk, K., Bulten, E., Klerkx, L., Dessein, J., Debruyne, L., Brunori, G., . . Metta, M. (2020). Digital transformation of agriculture, forestry and rural areas: Developing a futureproof socio-cyber-physical system. Retrieved from http://desira2020.eu/wp -content/uploads/2020/07/D1.1_CAF-report_I.pdf

Roberts, T. and Hernandez, K. (2019). Digital access is not binary: The 5 'A's of technology access in the Philippines. The Electronic Journal of Information Systems in Developing Countries, 85(4), e12084.

Rotz, S., Duncan, E., Small, M., Botschner, J., Dara, R., Mosby, I., ... Fraser, E. D. G. (2019). The politics of digital agricultural technologies: A preliminary review. Sociologia Ruralis, 59(2), 203-229.

Salemink, K., Strijker, D. and Bosworth, G. (2017). Rural development in the digital age: A systematic literature review on unequal ICT availability, adoption, and use in rural areas. Journal of Rural Studies, 54, 360-371. 
Sen, A. (2000). Social exclusion: Concept, application, and scrutiny. Social Development Papers No. 1, Mandaluyong: Asian Development Bank.

Scholz, R. W., Bartelsman, E. J., Diefenbach, S., Franke, L., Grunwald, A., Helbing, D., ... Montag, C. (2018). Unintended side effects of the digital transition: European scientists' messages from a proposition-based expert round table. Sustainability, 10(6), 2001.

Stichweh, R. and Windolf, P. (eds.) (2009). Inklusion und Exklusion: Analysen zur Sozialstruktur und sozialen Ungleichheit. VS Verlag für Sozialwissenschaften.

Trendov, N. M., Varas, S. and Zeng M. (2019). Digital technologies in agriculture and rural areas - Status report. Rome: FAO.

Tsan, M., Totapally, S., Hailu, M. and Addom, B. (2019). The digitalisation of African agriculture report 2018-2019. Wageningen: CTA.

USAID. (2020). USAID Digital Strategy 2020-2024. https://www.usaid.gov/ digitalstrategy

Van der Burg, S., Bogaardt, M. J. and Wolfert, S. (2019). Ethics of smart farming: Current questions and directions for responsible innovation towards the future. NJAS - Wageningen Journal of Life Sciences, 90/91, 100289.

Williamson, B. (2018). 10 definitions of datafication (in education). Accessed June 8, 2020, https://codeactsineducation.wordpress.com/2018/03/17/10-definitions-da tafication/ 